\title{
Determination of rutting distresses on hot mix asphalts by advanced techniques
}

\author{
Gabriel Skronka ${ }^{1, *}$, Martin $\mathrm{Jasso}^{2}$, and Otakar Vacin ${ }^{1}$ \\ ${ }^{1}$ Department of Transportation Systems, CTU in Prague, Praha, Czech Republic \\ ${ }^{2}$ Bituminous Materials Chair, Schulich School of Engineering, University of Calgary, Calgary, \\ Canada
}

\begin{abstract}
The sustainable use of non-renewable natural resources, such as asphalt binder, can be achieved by adequate planning. The proper assessment of asphalt binders is a prerequisite to the appropriate designing of road constructions that can eventually result in pavements in which the development of pavement distresses can be mitigated. Rutting is the most common distress occurring at high temperatures, which is frequently experienced by such countries as Indonesia; thus, the use of adequate asphalt binder in hot mix asphalt pavements results in long-lasting road constructions. By means of advanced techniques, e.g., multiple stress creep recovery test, conducted on a dynamic shear rheometer, it is possible to determine the rutting potential of asphalt binders. This technique, however, still seems to be imprecise at currently determined shear stress values. This paper aims to investigate on the example of ten different asphalt binders, if creep and recovery measured at higher shear stresses result in better correlation with rutting potential of hot mix asphalts than that at the standardized stress levels. Concurrently, other conventional asphalt binder properties (e.g., penetration, softening point, elastic recovery) are determined and compared with rutting.
\end{abstract}

\section{Introduction}

One of the main aspects that influence the quality of transportation is how well-built the roads are. Asphalt has been utilized as a construction material (mainly as insulation) since the beginning of recorded history. It was, however, the increasing popularity of the automobile in the early $20^{\text {th }}$ century that brought a massive demand for asphalt as a product of refineries. Since then, asphalt pavements constructed from graded aggregates and asphalt binder, prevail in highway engineering [1].

Typically, asphalt binder is used as a product of the vacuum distillation of crude oil. To improve its engineering properties, it is often air blown, or - to a much less extent - solvent methods might be used [2]. During service life, Hot Mix Asphalt (HMA) pavements experience various types of distresses, including rutting, thermal and fatigue cracking. Rutting is load-induced distress caused by shear stresses at high service temperatures [3-5]. The influence of the asphalt binders' rheological properties on the HMAs' resistance,

* Corresponding author: skronka.gabor@gmail.com 
besides the aggregates Job Mix Formula (JMF, also combined aggregate gradation) and the proportion of air voids, is beyond the reasonable doubt. Consequently, by using an asphalt binder adequate to the climate conditions and the traffic load, the development of permanent deformations might be prevented. Thus, to achieve effective and sustainable use of asphalt binders, accurate assessment is required.

Due to the combination of increasing traffic volume, higher stresses caused by higher axle loads, the frequency of loadings, and changing temperatures, it is essential to improve the full temperature range performance of asphalt binder during their service life. During the last three decades, polymer modified binders (PMBs) have become widely used in the paving industry. Polymer modification significantly improves both the low- and hightemperature performance of base asphalt binders and consequently helps to mitigate the creation of pavement distresses and extends the lifetime of asphalt roads. In general, polymer modification improves the rheological and engineering properties of asphalt binders (e.g. elastic response, tensile strength, adhesion, etc.) [6-9].

Empirical methods can distinguish between conventional asphalt binders with relative accuracy. However, they cannot reflect the new capabilities of polymer-modified binders, such as the elastic reaction of asphalt pavements to traffic loads, higher tensile strength and other properties. In 1993, the Strategic Highway Research Program (SHRP) started addressing this issue through the first version of the American Association of State Highway and Transportation Officials (AASHTO) specification M320 performance graded (PG) binder, also called the Superpave binder specification [10,11]. This new specification indicated that for rutting resistance, asphalt binders with both high complex shear modulus $\left(\mathrm{G}^{*}\right)$ and low phase angle $(\delta)$ are desirable. High complex shear modulus means a stiffer binder, while lower phase angle means more elastic binder. As a result of the SHRP research program, the high-temperature parameter of $\left|G^{*}\right| / \sin \delta$ for the evaluation of High Critical Temperature (HCT) was established. According to this research, above this temperature, the work dissipated after each load cycle becomes too high and manifests in permanent deformations.

This new specification was questioned by many researchers [12-14], as it is based on the study of unmodified binders and seems inappropriate for modified binders at higher temperatures. In response, the Federal Highway Administration (FHWA) has proposed a performance-based PG binder test for high-temperature performance of asphalt binders.

The Multiple Stress Creep Recovery (MSCR) test supplements the determination of HCT $\left(\left|\mathrm{G}^{*}\right| / \sin \delta\right)$ evaluated via Dynamic Shear Rheometer (DSR) $[15,16]$. The MSCR test shows a better correlation between the performance of modified binders and the rutting performance of asphalt mixes [14,17-19]. AASHTO M350 describes this test and implements it in the Standard Specification for Performance-Graded Asphalt Binder Using Multiple Stress Creep Recovery (MSCR) test with a designation of M332. The MSCR test has proven through numerous evaluations that it can, to some extent, distinguish between the differences in the rutting potentials of various binders, both modified and unmodified.

Test results indicate that the MSCR test may be a good supplement or even a possible replacement for the current HCT binder criteria of $\left|\mathrm{G}^{*}\right| / \sin \delta[17,19-22]$. Several studies $[17,22]$ suggest a good correlation between the rutting of asphalt mixtures (rut depth) and the non-recoverable creep compliance, Jnr, obtained at the shear stress $3.2 \mathrm{kPa}$. Others report that the evaluation of the Jnr at higher shear stress levels may be a more accurate determination of which binder is more rut resistant [19,23], possibly because the $3.2 \mathrm{kPa}$ stress level used in the current MSCR test may be lower than the stresses experienced in the pavement.

The presented research aims to investigate the collection of nine PMBs and one base asphalt to compare what stress level $(3.2 \mathrm{kPa}, 6.4 \mathrm{kPa}, 12.8 \mathrm{kPa}$, and $25.6 \mathrm{kPa})$ used at 
MSCR test would predict the binders' rut resistance in paving mixes more accurately - thus whether the presently used stress of $3.2 \mathrm{kPa}$ is the optimum selection.

\section{Materials and methods}

\subsection{Asphalt binders}

One base asphalt binder and nine polymer modified asphalt binders were used in this study. To achieve more generalized results, two different Pen grade base asphalt binders were modified. The first base asphalt binder was a 200/300 Pen grade asphalt characterized as PG 55-35 (True Grade). The second was a 300/400 Pen grade asphalt characterized as PG 50-37 (True Grade). A variety of polymers was used alone and in combination to modify the base asphalt. The third base asphalt binder was an 80/100 Pen grade asphalt characterized as PG 64-27 (True Grade).

\subsection{Polymers}

Asphalt binders were modified either by styrene-butadiene-styrene copolymer (SBS) or by Elvaloy $^{\circledR} 5160$ reactive elastomeric terpolymer (RET) from DuPont ${ }^{\mathrm{TM}}$. SBS, Kraton D1101 was characterized as a high molar mass linear triblock copolymer with a styrene content of 31 wt. \% from Kraton Performance Polymers. [24,25] A 20-mesh crumb rubber (CRM), made from vulcanized rubber reclaimed from old scrap tires, was also used for the modification of asphalt binders.

In addition to polymer modifiers, Innovalt ${ }^{\circledR}$ N400 polyphosphoric acid (PPA) was used either alone or in combination with Elvaloy ${ }^{\circledR} 5160$ to modify asphalt binders. Vacuum gas oil (VGO) was also added to asphalt binders to improve their low-temperature properties.

\subsection{Blend preparation}

Modifiers were used either alone or in combination with one another. Their content was adjusted to obtain modified asphalt binders with an HCT $\left(\left|\mathrm{G}^{*}\right| / \sin \delta\right)$ similar to True GradePG 64-Xx. Two of the modified asphalt binders were prepared from a 300/400 Pen grade base asphalt binder, while the other nine modified binders were prepared from a 200/300 Pen grade base asphalt. The 80/100 Pen grade asphalt was analyzed without any modification.

\subsection{Empirical tests}

Three conventional asphalt binder test methods (penetration, ring \& ball softening point, and elastic recovery) were conducted on all analyzed asphalt binders in accordance with the standards used in the European Union [26-28]. The penetration and elastic recovery values were measured at $25^{\circ} \mathrm{C}$.

\subsection{Functional test: multiple stress creep and recovery test}

A Kinexus Pro + rheometer was utilized in this study to perform the creep and recovery test. The standard MSCR test is performed on a $1 \mathrm{~mm}$-high cylindrical asphalt sample sandwiched between two $25 \mathrm{~mm}$-diameter parallel plates in a DSR. The test consists of ten cycles of $1 \mathrm{~s}$ shear creep loading, followed by $9 \mathrm{~s}$ of recovery phase at zero stress. Two 
shear stress levels of $0.1 \mathrm{kPa}$ and $3.2 \mathrm{kPa}$ are applied successively, beginning with the lower stress level. The resulting shear strain is monitored during the measurement. Fig. 1 shows 5 sequential cycles at two applied shear stress levels of the MSCR test. One cycle can be divided into 3 phases: initial strain $\left(\varepsilon_{0}\right)$, creep end strain $\left(\varepsilon_{\mathrm{c}}\right)$, and residual strain $\left(\varepsilon_{\mathrm{r}}\right)$. The initial strain is the initial shearing deformation at the beginning of the creep portion of each cycle, while creep end strain stands for the strain value at the end of the creep portion. Residual strain is the shearing deformation at the end of the recovery portion.

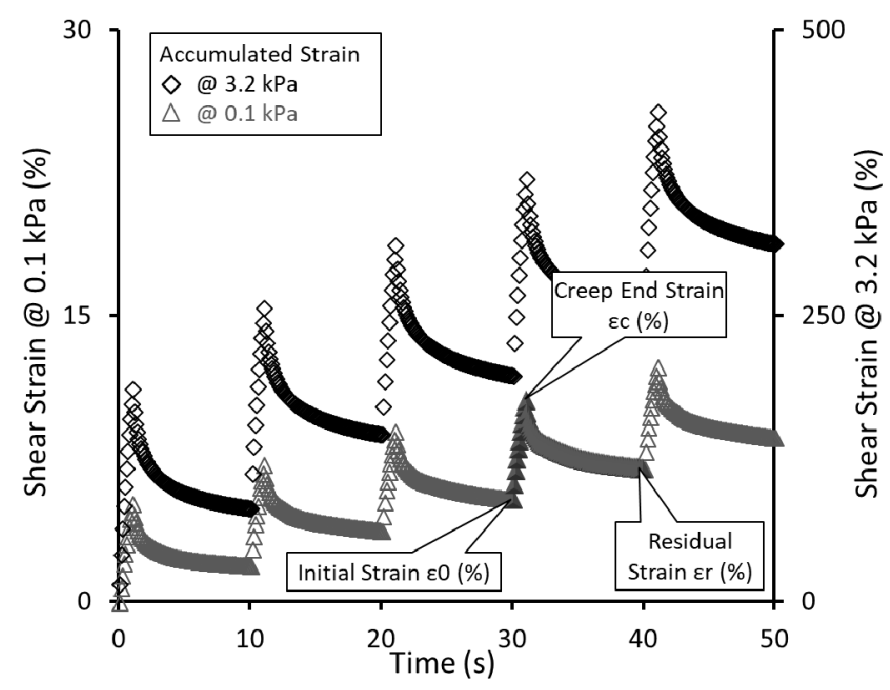

Fig. 1. Typical 5 cycles of creep and recovery test at standard stress levels.

The non-recovered strain is the adjusted strain value at the end of the recovery portion of each cycle $\left(\varepsilon_{\mathrm{r}}-\varepsilon_{0}\right)$. With the help of these measured strain values the non-recoverable creep compliance Jnr value is calculated in accordance with the eq. 1, where the nonrecovered strain is divided by the applied shear stress.

$$
J_{n r}\left(k P a^{-1}\right)=(\text { Non-recovered Strain / Applied Shear Stress })=\left(\varepsilon_{r}-\varepsilon_{0}\right) / \sigma
$$

During MSCR testing the resulting strain depends on the testing temperatures and the applied shear stress levels $\left(\sigma_{0,1}, \sigma_{3,2}\right)$. In this study, five stress levels were applied in the MSCR test: the two standard levels of $0.1 \mathrm{kPa}$ and $3.2 \mathrm{kPa}$, and three additional stress levels of $6.4 \mathrm{kPa}, 12.8 \mathrm{kPa}$, and $25.6 \mathrm{kPa}$. The goal was to evaluate the MSCR rutting potential of the asphalt binders at these different shear stresses. Eventually, as a nondimensional parameter, the non-recovered strain was compared with the rut depth results caused by the wheel-tracking device.

Evaluation of non-recovered strain values was conducted similarly for all binders. New samples were used for each increasing stress level. The first ten cycles of creep and recovery were conducted at $0.1 \mathrm{kPa}$ shear stress. At the end of the recovery portion of the tenth cycle at the creep stress level of $0.1 \mathrm{kPa}$, with no time lag between the cycles, either $3.2 \mathrm{kPa}, 6.4 \mathrm{kPa}, 12.8 \mathrm{kPa}$, or $25.6 \mathrm{kPa}$ of shear stress was successively applied to the same specimen for another ten cycles. The result was four new sets that were tested at one temperature for one asphalt binder $(0.1 \mathrm{kPa}$ and $3.2 \mathrm{kPa} ; 0.1 \mathrm{kPa}$ and $6.4 \mathrm{kPa}, 0.1 \mathrm{kPa}$ and $12.8 \mathrm{kPa}, 0.1 \mathrm{kPa}$ and $25.6 \mathrm{kPa}$ ).

All studied binders were tested at three different testing temperatures: $50^{\circ} \mathrm{C}, 60^{\circ} \mathrm{C}$, and $70^{\circ} \mathrm{C}$. The lowest temperature, $50^{\circ} \mathrm{C}$, is reasonably lower than the binders' $\mathrm{HCT}$ value, making it possible to investigate the binders' elastic properties and the influence of those 
properties on rutting resistance. The next temperature, $60^{\circ} \mathrm{C}$, is relatively close to the binders' HCT, but still below it. This temperature was selected to ensure that all the binders were conditioned at a lower temperature than their critical temperature. The third temperature, $70^{\circ} \mathrm{C}$, is above the binders' $\mathrm{HCT}$ value.

\subsection{Hot mix asphalt preparation}

Hot mix asphalt with the maximum aggregate size of $16 \mathrm{~mm}$, conventionally used as a surface course, was chosen for testing. The preparation of the hot mix asphalt samples was conducted according to the Superpave mix design method [29]. The desired combined aggregate gradation consisted of five different mineral aggregate fractions of $16 \mathrm{~mm}, 12.5$ $\mathrm{mm}, 5 \mathrm{~mm}$, manufactured fines (MF), and washed MF. The combined gradation of these five aggregates had a nominal maximum aggregate size of $12.5 \mathrm{~mm}$, which conformed to the minimum and maximum gradation requirements specified in Table 3 of AASHTO M323-12 [30].

When preparing the asphalt mixes as described in AASHTO R30-02 [31], the same combined aggregate gradation was used, and the same short-term mixture conditioning procedure was conducted to ensure that the only difference between the mixes was the type of the asphalt binder. The volume of asphalt binder in the mixes was set to $5.9 \%$ (wt. \%).

\subsection{Wheel tracking test (WTT)}

WTT was conducted on asphalt mix samples at $60^{\circ} \mathrm{C}$ to evaluate the hot mix asphalts' resistances to rutting. This was done in accordance with EN 12697-22+A1, the specifications used in the European Union [30].

At least two $320 \times 260 \times 50 \mathrm{~mm}$ slab specimens from every asphalt mix were prepared in a hydraulic compactor. The slab specimens were fixed in steel molds at a constant temperature of $60^{\circ} \mathrm{C}$. A temperature control system maintained the temperature via hot air in a cabinet.

A wheel with a 20x50mm solid rubber hoop and an outside diameter of $200 \mathrm{~mm}$ reciprocated on the surface of each specimen. The rubber hoop applied a $700 \mathrm{~N}$ load on a $22 \times 50 \mathrm{~mm}$ transient area [3]. The wheel-tracking device system measured the rut depth using an LVDT transducer located in the middle of the specimen. The wheel continued to reciprocate either until it had completed 10,000 cycles or until the impression reached a depth of $20 \mathrm{~mm}$.

The depth of the impression and the ambient temperature in the cabinet were recorded by an internal data acquisition and control system. The rut depth results were reported as the average value of both specimens expressed as a non-dimensional parameter (strain), calculated by dividing the average impression by the average thickness of the slab.

\section{Results and discussion}

The objective that similar high critical temperature (PG64-xx) ought to be reached for all binders was achieved with a maximum divergence of about $\pm 3^{\circ} \mathrm{C}$. All binders met this criterion once they experienced RTFO short-term aging.

Table 1 shows the conventional test results, such as penetration and elastic recovery, both conducted at $25^{\circ} \mathrm{C}$, and the (ring \& ball) softening point results. Table 1 summarizes the HCTs of all binders before and after they experienced RTFO short-term aging. According to the penetration test results, beside the 80/100 Pen graded base binder, the PPA-modified binder shows the highest hardness. Softening point results show that the binders, modified 
from the softest base binders, became the hardest ones. Furthermore, elastic recovery results suggest that once the applied stress ceased, the SBS-modified and the RET+PPAmodified binders recovered the most.

Table 1. High critical temperature values and conventional test results.

\begin{tabular}{|c|c|c|c|c|c|c|}
\hline $\begin{array}{c}\text { Base } \\
\text { binder }\end{array}$ & $\begin{array}{l}\text { Polymer Type } \\
\text { designation }\end{array}$ & $\begin{array}{c}\text { Penetration } \\
\text { at } 25^{\circ} \mathrm{C} \\
(\mathbf{m m})\end{array}$ & $\begin{array}{l}\text { Softening } \\
\text { point }\left({ }^{\circ} \mathrm{C}\right)\end{array}$ & $\begin{array}{c}\text { ER at } \\
25^{\circ} \mathrm{C}(\%)\end{array}$ & $\begin{array}{r}\text { HCT } \\
\left({ }^{\circ} \mathrm{C}\right)\end{array}$ & $\begin{array}{c}\text { HCT }_{\text {(RTFO) }} \\
\left({ }^{\circ} \mathrm{C}\right)\end{array}$ \\
\hline $80 / 100$ & None & 91 & 47.2 & 10.0 & 64.8 & 64.8 \\
\hline \multirow{7}{*}{$200 / 300$} & $\mathrm{RET}+\mathrm{PPA}$ & 149 & 53.3 & 78.0 & 65.5 & 65.9 \\
\hline & RET & 172 & 53.2 & 69.0 & 62.7 & 62.9 \\
\hline & $\mathrm{RET}+\mathrm{SBS}$ & 149 & 45.8 & 53.5 & 63.5 & 64.4 \\
\hline & SBS & 141 & 54.3 & 97.5 & 63.7 & 63.9 \\
\hline & PPA & 124 & 54.6 & 31.0 & 64.4 & 64.0 \\
\hline & $\mathrm{RET}+\mathrm{PPA}+\mathrm{CRM}$ & 150 & 46.1 & 52.5 & 64.0 & 64.6 \\
\hline & $\mathrm{SBS}+\mathrm{S}+\mathrm{CRM}$ & 156 & 42.8 & 57.0 & 63.5 & 66.9 \\
\hline \multirow{2}{*}{$300 / 400$} & $\mathrm{SBS}+\mathrm{S}$ & 169 & 63.8 & 94.5 & 70.0 & 64.4 \\
\hline & $\mathrm{SBS}+\mathrm{S}+\mathrm{VGO}$ & 205 & 66.8 & 99.5 & 72.7 & 64.3 \\
\hline
\end{tabular}

Table 2. Hot mix asphalt specimen properties and the wheel tracking test results.

\begin{tabular}{|c|c|c|c|c|c|c|}
\hline $\begin{array}{c}\text { Base } \\
\text { binder }\end{array}$ & $\begin{array}{l}\text { Polymer type } \\
\text { designation }\end{array}$ & $\underset{\left(\mathrm{kg} / \mathrm{m}^{3}\right)}{\mathbf{G}_{\mathbf{m b}}}$ & $V_{a}(\%)$ & VMA (\%) & VFA (\%) & WTT (\%) \\
\hline $80 / 100$ & None & 2.279 & 6.8 & 17.760 & 61.625 & 9.74 \\
\hline \multirow{7}{*}{$200 / 300$} & $\mathrm{RET}+\mathrm{PPA}$ & 2.284 & 6.6 & 17.589 & 62.364 & 8.49 \\
\hline & RET & 2.300 & 6.0 & 17.010 & 64.930 & 10.88 \\
\hline & $\mathrm{RET}+\mathrm{SBS}$ & 2.317 & 5.3 & 16.406 & 67.816 & 14.31 \\
\hline & SBS & 2.296 & 6.1 & 17.173 & 64.189 & 15.73 \\
\hline & PPA & 2.294 & 6.2 & 17.228 & 63.942 & 28.25 \\
\hline & $\mathrm{RET}+\mathrm{PPA}+\mathrm{CRM}$ & 2.272 & 7.1 & 18.013 & 60.590 & 13.70 \\
\hline & $\mathrm{SBS}+\mathrm{S}+\mathrm{CRM}$ & 2.282 & 6.7 & 17.670 & 62.112 & 15.59 \\
\hline \multirow{2}{*}{$300 / 400$} & $\mathrm{SBS}+\mathrm{S}$ & 2.294 & 6.2 & 17.222 & 63.984 & 10.59 \\
\hline & $\mathrm{SBS}+\mathrm{S}+\mathrm{VGO}$ & 2.296 & 6.1 & 17.167 & 64.212 & 11.32 \\
\hline
\end{tabular}

The rut resistances of the HMAs are influenced by the combined aggregate gradation, the type, and content of asphalt binder in the mixture, and the volumetric properties of the 
compacted asphalt mixture specimens. The most important volumetric properties of the compacted specimens, such as specific gravity $(\mathrm{Gmb})$, air void (Va), voids in the mineral aggregate (VMA), and voids filled with asphalt (VFA), are presented in Table 2. The HMA test specimens were typically compacted to $6.2 \pm 0.9 \%$ air voids. The WTT asphalt mix results, expressed in percent deformation (i.e. strain) and related to the average thickness of each specimen, are also shown in Table 2 . According to the WTT conducted at $60^{\circ} \mathrm{C}$, the most rut resistant mix contained RET+PPA-modified binder. The second most rut resistant mix contained 80/100 Pen grade base binder. The least resistant mix contained 200/300 Pen grade base binder blended with PPA.

\subsection{Conventional test results vs WTT results}

Empirical properties of penetration, softening point (ring \& ball), and elastic recovery are compared with WTT rut depth results expressed as a non-dimensional parameter (strain). Out of all ten binders used in this study, three were blended from other than 200/300 Pen grade base binder. Considering this, in addition to the comparison of all ten asphalt binders the regression function of each binder, prepared from the 200/300 Pen grade base asphalt (hereinafter referred to as "Only 200/300"), is plotted in each graph. In this case, binders prepared from the 300/400 Pen grade base asphalt and the 80/100 Pen grade asphalt are omitted.
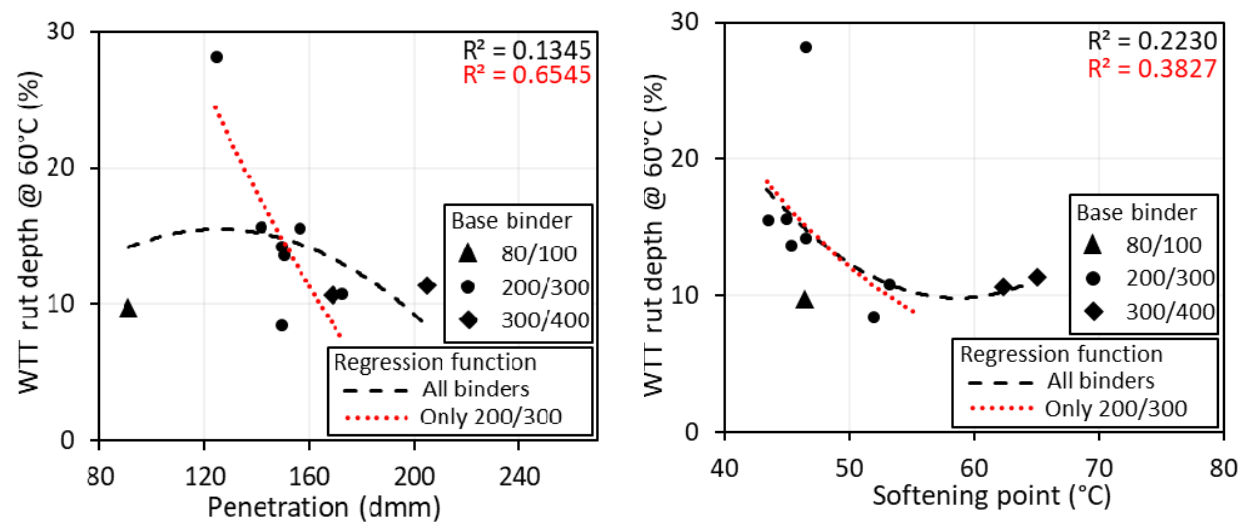

Fig. 2. Penetration at $25^{\circ} \mathrm{C}$ and softening point versus WTT results at $60^{\circ} \mathrm{C}$.

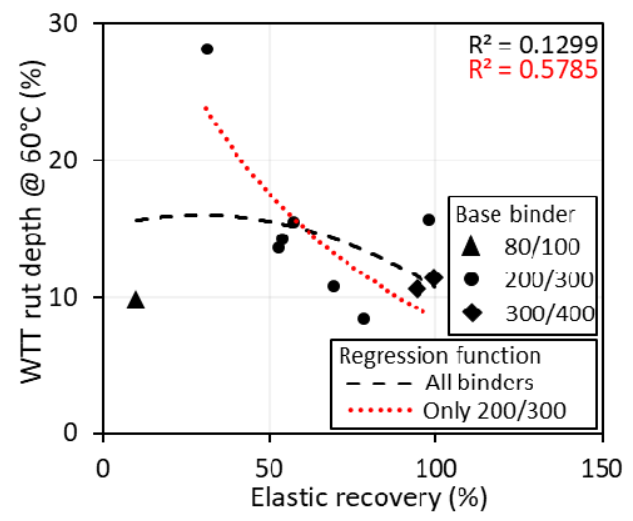

Fig. 3. Elastic recovery at $25^{\circ} \mathrm{C}$ versus WTT results at $60^{\circ} \mathrm{C}$. 
Fig. 2-3 show the relationship between the softening point, the penetration, elastic recovery and the WTT rut depths. The penetration and the elastic recovery test were conducted at $25^{\circ} \mathrm{C}$. It is apparent from Fig. 2-3 that no significant correlation can be found between the empirical test results and the asphalt mixes' rut depths. Furthermore, in the case of penetration, the correlation function shows an opposite trend than what would be expected, i.e., harder binders tend to be less rut resistant in asphalt mixes. Although the correlation was slightly higher in case of binders prepared from the 200/300 Pen grade base asphalt (“Only 200/300”), it was still negligible.

\subsection{Performance related test results vs WTT}

Fig. 4-6 present the results of MSCR and WTT testing of the selected collection of asphalt binders where the values of non-recovered strain (in the following figures denoted as $\varepsilon_{\mathrm{r}}, \%$ ) are correlated with rut depth (strain, \%).
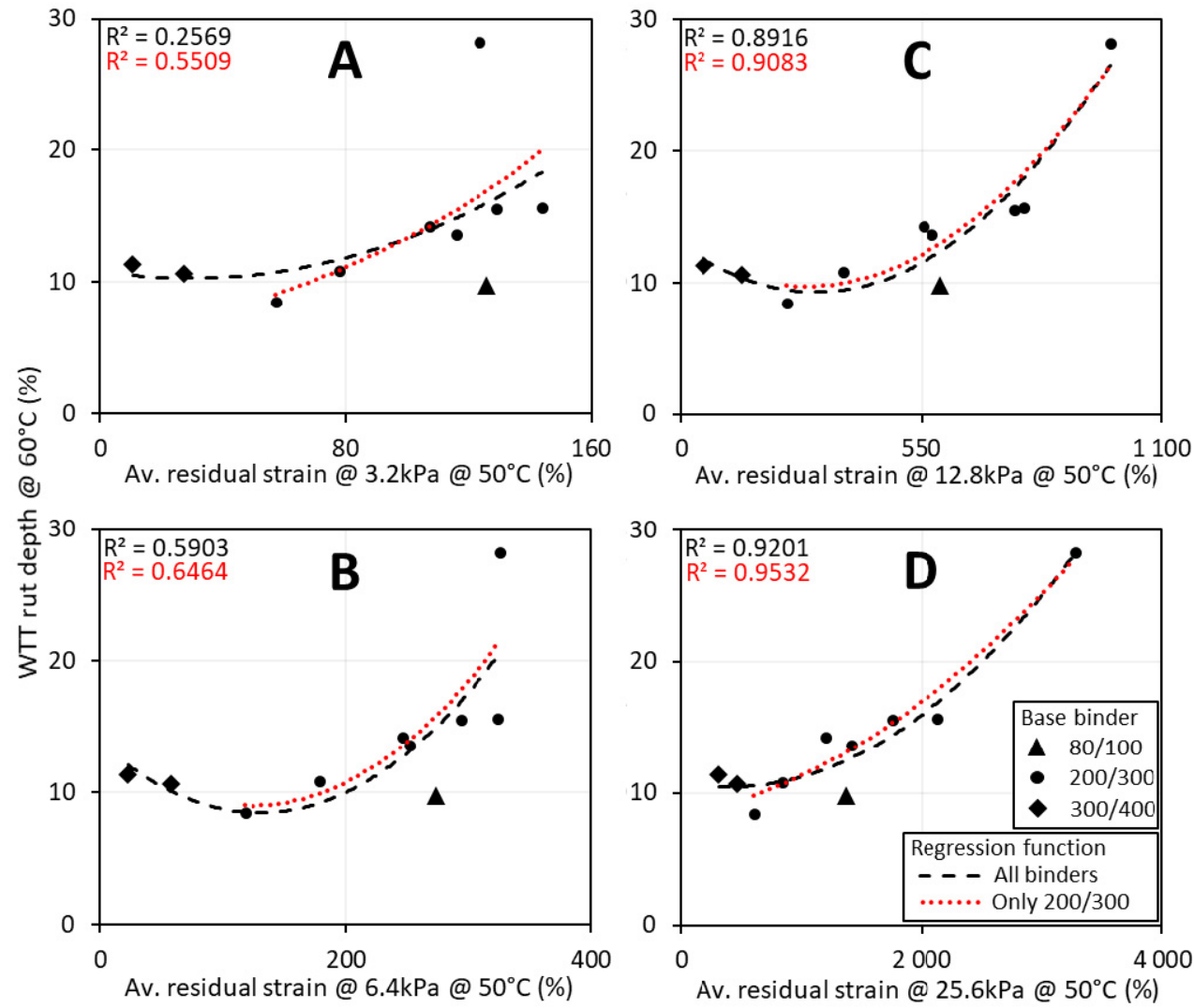

Fig. 4. Non-recovered strain at different shear stresses at $50^{\circ} \mathrm{C}$ versus WTT rut depth at $60^{\circ} \mathrm{C}$.

Fig. 4-6 show the MSCR test results evaluated at $50^{\circ} \mathrm{C}, 60^{\circ} \mathrm{C}$, and $70^{\circ} \mathrm{C}$, respectively. Each figure represents the results of the MSCR test evaluated at different shear stress loadings. The correlation between the MSCR test results conducted at $0.1 \mathrm{kPa}$ and the rut depth was never higher than $\mathrm{R} 2=0.2$; hence, the results evaluated at this stress level will not be shown in this study.

The MSCR results evaluated at the standard stress level $(3.2 \mathrm{kPa})$ at $50^{\circ} \mathrm{C}$, which is two grades lower than the binders' critical temperature, show only a low correlation between 
the asphalt mixes' rut depths and the binders' non-recovered strain (Fig. 4A). Measurements conducted at higher shear stress levels of $6.4 \mathrm{kPa}$ (Fig. 4.B), $12.8 \mathrm{kPa}$ (Fig. 4C), and even $25.6 \mathrm{kPa}$ (Fig. 4D) resulted in a better correlation. The results show that the PPA-modified binder is the most stress sensitive. The most relevant measurements from the testing temperature of $50^{\circ} \mathrm{C}$ is obtained at $12.8 \mathrm{kPa}$ and $25.6 \mathrm{kPa}$.

The SBS+S+VGO and SBS+S blends that were prepared from a 300/400 Pen grade base asphalt and the 80/100 Pen grade base asphalt all tended to diverge from the expected values. For instance, binders prepared with a modified 300/400 Pen grade base asphalt mixes performed worse than it would be assumed from the MSCR test results. This deflection results in a parabola-like regression function instead of an increasing function. The asphalt mix prepared from the 80/100 Pen grade base asphalt, however, seemed to be more rut resistant than it could be assumed from the MSCR test results. This suggests that the results, regardless of their HCT values and even of their performance in MSCR testing, depend also on the base asphalt consistency (stiffness, viscosity).
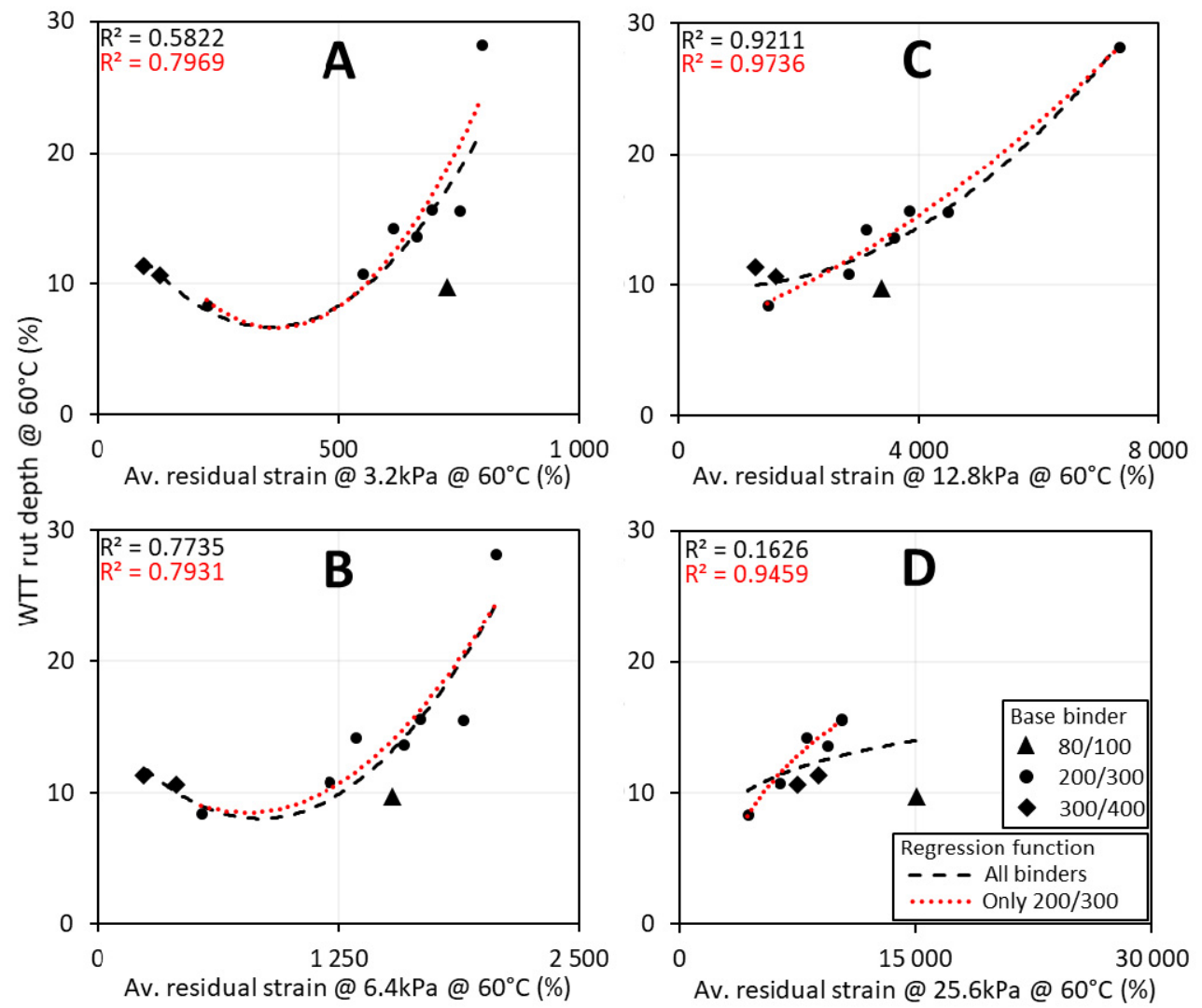

Fig. 5. Non-recovered strain at different shear stresses at $60^{\circ} \mathrm{C}$ versus WTT rut depth at $60^{\circ} \mathrm{C}$.

When considering only the asphalt binders blended from 200/300 Pen grade base asphalt, the regression function slightly improves. Similarly as above, the results of MSCR testing at shear stresses of $12.8 \mathrm{kPa}$ and $25.6 \mathrm{kPa}$ at $50^{\circ} \mathrm{C}$ showed the best correlation with the WTT rut depth results.

Fig. 5 shows the MSCR results obtained at $60^{\circ} \mathrm{C}$, the same temperature at which the WTT was conducted. These results show distinctively improved correlation with the WTT results at the standard shear stress level of $3.2 \mathrm{kPa}$ (Fig. 5A) and an elevated shear stress 
level of $6.4 \mathrm{kPa}$ (Fig. 5B) compared to the MSCR results obtained at $50^{\circ} \mathrm{C}$ and the same stress levels. The MSCR results obtained at a shear stress level of $12.8 \mathrm{kPa}$ (Fig. 5C) correlate even better with the mix's WTT rutting performance. The extremely low rut resistance of the PPA-modified binder was first revealed at $12.8 \mathrm{kPa}$ shear stress level and MSCR testing temperature of $60^{\circ} \mathrm{C}$.

The MSCR test performed at a temperature of $60^{\circ} \mathrm{C}$ and shear stress of $25.6 \mathrm{kPa}$ (Figure 5.D) resulted in a complete separation of the sample of the PPA-modified binder, as the upper and lower plates of the DSR rheometer were no longer connected. It appears that creep recovery measurements conducted at a shear stress of $25.6 \mathrm{kPa}$ and the binders' critical temperature are unreliable and may cause complete damage to the tested sample.
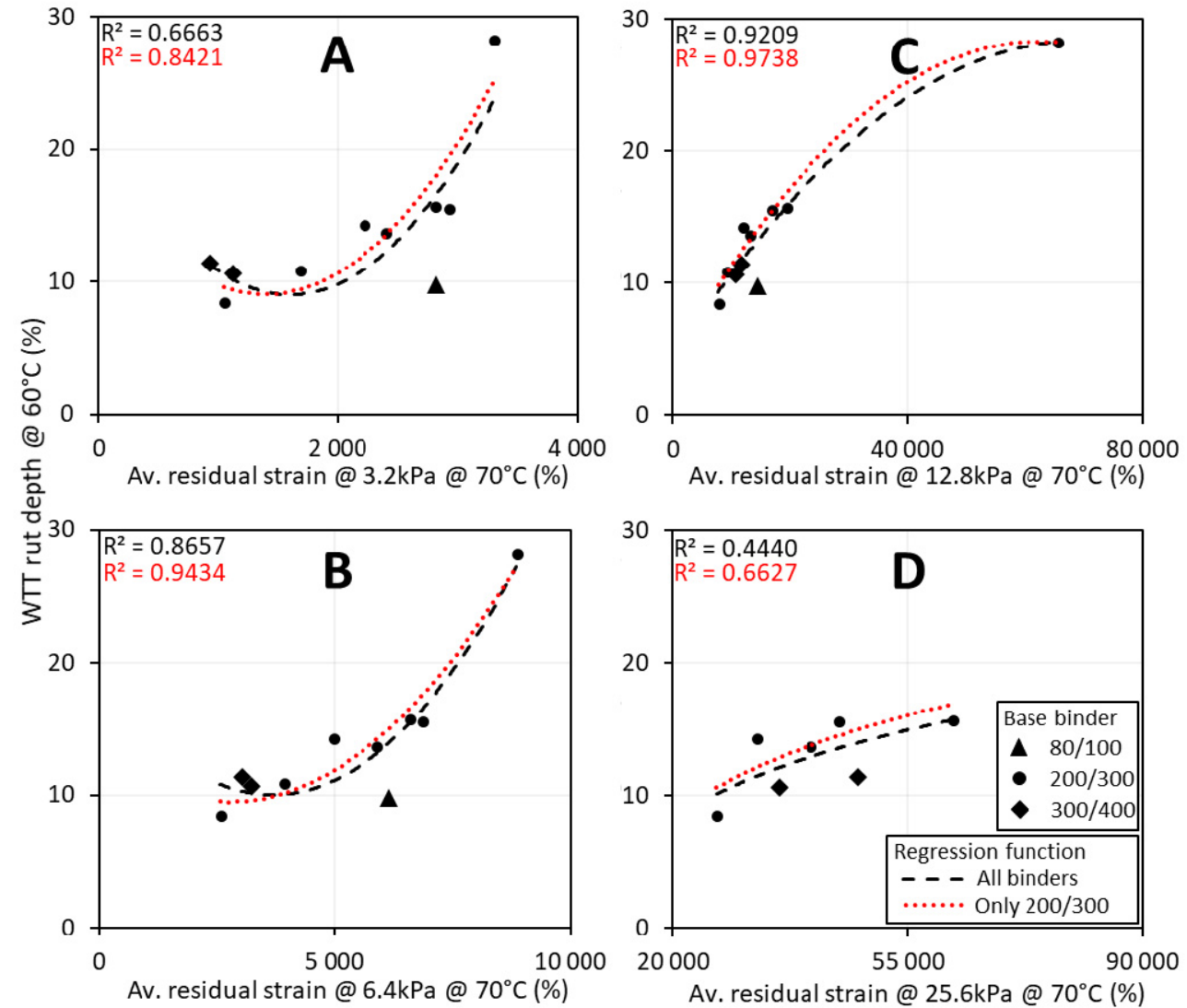

Fig. 6. Non-recovered strain at different shear stresses at $70^{\circ} \mathrm{C}$ versus WTT rut depth at $60^{\circ} \mathrm{C}$.

Similar to MSCR testing performed at $50^{\circ} \mathrm{C}$, MSCR testing performed at $60^{\circ} \mathrm{C}$ overestimates the WTT rut resistance of binders prepared with the 300/400 Pen grade base asphalt that was modified by $\mathrm{SBS}+\mathrm{S}+\mathrm{VGO}$ and $\mathrm{SBS}+\mathrm{S}$ respectively. On the other hand, testing also underestimates the WTT rut resistance of 80/100 Pen grade base asphalt.

Fig. 6 shows the results of an MSCR test conducted at $70^{\circ} \mathrm{C}$, which is on average one PG grade higher than the binders' HCT. These results showed a better correlation with the rut depth of HMAs at $6.4 \mathrm{kPa}$ shear stress than with the results obtained at $12.8 \mathrm{kPa}$. Stress levels of $12.8 \mathrm{kPa}$ and higher could not be applied at this temperature since testing at this combination of high temperature, and high-stress level caused inaccurate measurements and separation of several samples. 
Where the testing results and correlation of MSCR vs. WTT at all temperatures and stresses are assessed, they suggest that $6.4 \mathrm{kPa}$ shear stress during MSCR testing across a wide range of temperatures yields better correlation with WTT mix testing results than the presently recommended $3.2 \mathrm{kPa}$ of shear stress.

When considering only the asphalt binders produced with 200/300 Pen grade base asphalt, the results obtained at 3.2 and $6.4 \mathrm{kPa}$ show a significant correlation between the MSCR and WTT data. Let it be noted that above the binders' critical temperatures better correlations between MSCR and WTT can be achieved by conducting the MSCR test at lower shear stress levels.

It is evident that there is a correlation between the non-recovered strain value at the MSCR test and the WTT rut depth. Results show that the use of higher shear stresses in the MSCR test helps to better eliminate the poor performers in the hot mix asphalt pavements. According to the results shown in Fig. 4-6, the MSCR tests conducted at low shear stresses can accurately evaluate only certain types of binders. The MSCR test either overestimates or underestimates the performance of binders prepared from different base asphalts. The rut resistance of the binder in an HMA seems to be more dependent on the hardness of the base binder it was prepared from, than on the elasticity it gains by modification. As a result, the application of an even higher stress level of $12.8 \mathrm{kPa}$ around the binder's critical temperature can be recommended. At lower temperatures, even higher stress levels like $25.6 \mathrm{kPa}$ might be considered desirable.

\section{Conclusions}

The present paper aims to investigate the relationship between the rut resistance of the asphalt mixes and the asphalt binders' properties. Three basic empirical asphalt binder properties (softening point, penetration, elastic recovery) and creep, and recovery test result was compared with wheel tracking test result of asphalt mixes. The creep and recovery test was performed at several temperatures below, at, and above the binders' high critical temperature $\left(\left|\mathrm{G}^{*}\right| / \sin \delta\right)\left(50^{\circ} \mathrm{C}, 60^{\circ} \mathrm{C}, 70^{\circ} \mathrm{C}\right)$ and at five different shear stress levels ranging from $0.1 \mathrm{kPa}$ to $25.6 \mathrm{kPa}$.

Ten asphalt binders, prepared from three vacuum distillation residues of different hardness (80/100 Pen grade, 200/300 Pen grade, and 300/400 Pen grade), were analyzed in this study. The two softer vacuum residues were used as a base for modification by different polymers and their combinations, producing 9 polymer modified asphalt binders. The 80/100 Pen grade base asphalt was used without modification.

The base asphalts were blended with four different modifiers: SBS polymer, RET, PPA, and CRM. In some cases, the SBS polymer was cross-linked by sulfur in the asphalt/polymer blend. In one case, VGO was added to the mix.

Asphalt mixes were prepared from the analyzed asphalt binders using uniform mix design. Wheel tracking test performed at $60^{\circ} \mathrm{C}$ was conducted on each paving mix prepared using different asphalt binder to evaluate the contribution of different asphalt binders to rut resistance of standard asphalt mix.

In general, comparison of the binders' analyzed properties with their rut resistance in asphalt mixes, suggest the following: 1) Empirical properties such as penetration, softening point, and elastic recovery cannot satisfactorily correlate with the rut resistance of the asphalt mixes; 2) Creep and recovery test results indicate that standard MSCR stress levels of $0.1 \mathrm{kPa}$ and $3.2 \mathrm{kPa}$ do not always satisfactory correlate with the rut resistance of asphalt mixes; 3) Application of higher shear stress of $6.4 \mathrm{kPa}$ in MSCR tests performed at wide range of temperatures provided the overall best correlation between the MSCR results and the results of the rutting test of asphalt mixes; 4) MSCR measurements conducted at 12.8 $\mathrm{kPa}$ of shear stress and around (or below) the high critical temperature of $\left|G^{*}\right| / \sin \delta$ can 
provide the best correlation between the MSCR test and rutting results in wheel tracking test. If the MSCR test is performed at temperature two PG grades below the binder's critical temperature, however, even higher shear stress levels can be applied and have a good MSCR/WTT correlation; 5) The results of the MSCR test and WTT test point to the fact that modified asphalt binders that may have similar Superpave properties $\left(\left|G^{*}\right| / \sin \delta\right.$, MSCR) prepared from different base asphalts (harder, softer - viscosity, stiffness, etc.) exhibit different resistance to rutting in asphalt mixes. It appears that the harder the base asphalt the better the rut resistance of the paving mix regardless the binder elasticity and other parameters. This is an extremely important finding that begs to rethink and reevaluate high temperature binder performance parameters (including MSCR) and their validity over a wide range of modified binders produced from different base asphalts and different polymers and other materials and their combinations.

We gratefully acknowledge the help provided by Dr. Ludo Zanzotto and Dr. Jiri Stastna during this research. This study was made possible by a grant from CTU of Prague no.: SGS18/092/OHK2/1T/16

\section{References}

1. C. Yang, J. Xie, X. Zhou, Q. Liu, L. Pang, Materials (Basel) 11, 5 (2018)

2. J.G. Speight, Asphalt materials science and technology (Butterworth-Heinemann, Oxford, 2016)

3. J. Žák, J. Vavřička, Proc. of the Transcom 2011 (2011)

4. J.R. Mattos, W.P. Núñez, J.A. Ceratti, A. Zíngano, W. Fedrigo, Proc. of the 6th Eurasphalt Eurobitume Congress (2016)

5. K. Su, L. Sun, Y. Hachiya, R. Maekawa, Proc. of the 6th ICPT (2008)

6. J. Zhu, B. Birgisson, N. Kringos, Eur. Polym. J. 54 (2014)

7. J. Read, R.N. Hunter, A. Self, The shell bitumen handbook (Thomas Telford, London, 2015)

8. L.H. Lewandowski, Rubber Chem. Tech. 67 (1994)

9. Y. Yildirim, Con. Build. Mat. 21 (2007)

10. R. Dongré, J. D’Angelo, G. Reinke, A. Shenoy, Transp. Res. Rec. (2004)

11. AASHTO, Standard Specification for Performance-Graded Asphalt Binder M320-16 (American Association of State Highway and Transportation Officials, Washington D.C., 2016)

12. H.U. Bahia, D.I. Hanson, M. Zeng, H. Zhai, M.A. Khatri, R.M. Anderson, Characterization of modified asphalt binders in superpave mix design (Natl. Coop. Highw. Res. Progr. 2001)

13. A. Shenoy, J. Transp. Eng. 127 (2001)

14. M. Bouldin, R. Dongré, J. D’Angelo, Transp. Res. Rec. 1766 (2001)

15. AASHTO, Standard Specification for Performance-graded Asphalt Binder using Multiple Stress Creep Recovery (MSCR) Test M332-14 (American Association of State Highway and Transportation Officials, Washington D.C., 2014)

16. AASHTO, Standard Method of Test for Multiple Stress Creep Recovery (MSCR) Test of Asphalt Binder Using a Dynamic Shear Rheometer (DSR) T350-14 (American Association of State Highway and Transportation Officials, Washington D.C., 2014)

17. J. Zhang, L.F. Walubita, A.N.M. Faruk, P. Karki, G.S. Simate, Con. Build. Mat. 94 (2015) O.-V. Laukkanen, H. Soenen, T. Pellinen, S. Heyrman, G. Lemoine, Mater. 
Struct. 48 (2015)

18. J.A. D'Angelo, Development of a performance based binder specification for rutting using creep and recovery testing (University of Calgary, Calgary, 2009)

19. J.A. D’Angelo, R.Q. Kluttz, R. Dongre, K. Stephens, J. Assoc. Asph. Paving Tech. 76 (2007)

20. A.P. Dueñas, A.P. Lepe, E.M. Martinez, V.C. Ibañez, Proc. of the 5th Eurasphalt Eurobitume Congress E\&E2012 (2012)

21. C. Robertus, R. Van Rooijen, L. Thimm, Proc.of the 5th Eurasphalt Eurobitume Congress E\&E2012 (2012)

22. S. Dreessen, T. Gallet, Proc.of the 5th Eurasphalt Eurobitume Congress E\&E2012 (2012)

23. G. Polacco, J. Stastna, D. Biondi, F. Antonelli, Z. Vlachovicova, L. Zanzotto, J. Colloid Interface Sci. 280 (2004)

24. M. Jasso, R. Hampl, O. Vacin, D. Bakos, J. Stastna, L. Zanzotto, Fuel Process. Tech. 140 (2015)

25. European Standard, Bitumen and Bituminous Binders - Determination of the Softening Point - Ring and Ball Method EN 1427 (European Committee for Standardization, 2015)

26. European Standard, Bitumen and Bituminous Binders - Determination of needle penetration EN 1426 (European Committee for Standardization, 2015)

27. European Standard, Bitumen and bituminous binders - Determination of the Elastic Recovery of Modified Bitumen EN 13398 (European Committee for Standardization, 2010)

28. AASHTO, Standard Practice for Superpave Volumetric Design for Hot-Mix Asphalt (HMA) R35-12 (American Association of State Highway and Transportation Officials, Washington D.C., 2012)

29. AASHTO, Standard Specification for Superpave Volumetric Mix Design M 323-12 (American Association of State Highway and Transportation Officials, Washington D.C., 2012)

30. AASHTO, Standard Practice for Mixture Conditioning of Hot-Mix Asphalt (HMA) R 30-02 (American Association of State Highway and Transportation Officials, Washington D.C., 2002) 